\title{
Overview of the 81st Scientific Sessions of the American Diabetes Association
}

\author{
Dr Caroline Day logs in to the meeting whisked \\ from Washington DC to the worldwide web \\ 25th-29nd June, 2021
}



\section{Introduction}

As COVID-19 continued to hold the world to ransom, the American Diabetes Association (ADA) again transitioned the annual scientific sessions from the real world to the virtual world. Despite the assumed eco-friendliness and 'stay-at-home' convenience of this year's meeting, participant numbers were again lower $(\sim 11,500)$ than when the last physical meeting was held $(>15,000)$ - perhaps the diabetes world prefers active transfer of information.

The final programme for the 2021 Scientific Sessions has a useful 'Day-at-a-glance schedule' with the detailed timetable to permit presentation/poster selection commencing on page 27. The complete 220-page document can be downloaded from https://res.cloudinary.com/freemanoeptest/im age/upload/v1624327340/OEPro \%20\%202021\%20Events/ada2021/2021_Final_P rogram_tisytf.pdf and the Scientific Sessions Abstracts (including later breakers) are published online as a supplement to the journal Diabetes (Volume 70, Suppl 1; https://diabetes.diabetesjournals.org/content/scientificsessions-abstracts).

The 2021 Scientific Sessions abstracts, posters and webcasts can be accessed at https://professional.diabetes.org/contentpage/previous-scientific-sessions-abstractsposters-and-webcasts and the ADA 2021 highlights (www.adahighlights.com) offer free daily highlights plus conference summaries, expert overviews and commentaries plus interviews with key speakers and the ADA leadership as well as poster podcasts and downloadable slides.

\section{Highlights}

As always, the named lectures are worth perusing (Table 1). Unsurprisingly, COVID featured strongly at this meeting, with several presentations drawing attention to the interplay between the virus and diabetes and strategies to reduce risk and optimise positive outcomes in those infected (symposia: 25 June, $8 \mathrm{am}$ and 2pm; 27 June, 2.15pm and 4.30pm; 28 June, 4.30pm; plus 103 COVIDrelated abstracts).

The DARE-19 study reported on 27 June

Table 1 Awards 2021

\begin{tabular}{|c|c|}
\hline National Scientific \& Health Care Achievement Awards and Lectures & Recipient \\
\hline $\begin{array}{l}\text { Banting Medal for Scientific Achievement Award } \\
\text { Lecture: In the beginning was the gut - and then something happened - } \\
\text { a story about the incretins. (Sunday, } 27 \text { June, 10.15am) }\end{array}$ & Jens J Holst, Denmark \\
\hline $\begin{array}{l}\text { Kelly West Award for Outstanding Achievement in Epidemiology } \\
\text { Lecture: Risk factors and type } 2 \text { diabetes. (Sunday, } 27 \text { June, } 2.15 \mathrm{pm} \text { ) }\end{array}$ & Nicholas J Wareham, UK \\
\hline $\begin{array}{l}\text { Outstanding Scientific Achievement Award } \\
\text { Lecture: Unique cardiometabolic mechanisms and consequences of } \\
\text { youth-onset type } 1 \text { and type } 2 \text { diabetes. (Monday, } 28 \text { June, 10.10am) }\end{array}$ & Kristen J Nadeau, USA \\
\hline $\begin{array}{l}\text { Outstanding Educator in Diabetes Award } \\
\text { Lecture: It Takes a Brain, a Heart, Courage, ... Support. } \\
\text { (Saturday, } 26 \text { June, 10.15am) }\end{array}$ & $\begin{array}{l}\text { Denise Charron-Prochownik, } \\
\text { USA }\end{array}$ \\
\hline Outstanding Achievement in Clinical Diabetes Research Award & $\begin{array}{l}\text { Hans-Henrik Parving, } \\
\text { Denmark }\end{array}$ \\
\hline Outstanding Physician-Clinician in Diabetes Award & Silvio E Inzucchi, USA \\
\hline Albert Renold Award & Bruce M. Spiegelman, USA \\
\hline $\begin{array}{l}\text { Harold Rifkin Award for Distinguished International Service in the } \\
\text { Cause of Diabetes }\end{array}$ & $\begin{array}{l}\text { Juleen R Zierath, Sweden/ } \\
\text { Denmark }\end{array}$ \\
\hline
\end{tabular}

Professional Interest Group Award Lectures

Edwin Bierman Award (Complications)

Russell A DeBose-Boyd, USA

Lecture: Posttranslational control of HMG COA reductase - The molecular target of cholesterol-lowering statins. (Saturday, 26 June,1.45pm)

Norbert Freinkel Award (Pregnancy)

Lecture: Therapeutic advances in pregnancy for women with pre-existing

diabetes - How far have we come? (Saturday, 26 June, 4pm)

Roger Pecorara Award (Foot care)

Lecture: Causation research on diabetic foot complications - What I

learned from Roger Pecoraro? (Monday, 28 June, 2.15pm)

Richard R Rubin Award (Behavioural Medicine and Psychology)

Lecture: Diabetes prevention and treatment in the American southwest

(Saturday, 26 June, 1.45pm)

Denise Feig, Canada

Edward J Boyko, USA

David G Marrero, USA

(2pm) and included a live question-answer session. In this international study in patients with cardiometabolic risk hospitalised due to COVID-19, patients were assigned to dapagliflozin $10 \mathrm{mg}(\mathrm{n}=625)$ or placebo $(n=625)$. Although dapagliflozin appeared to improve outcomes (eg, recovery $87.5 \%$ vs $85.1 \%$; death $6.6 \%$ vs $8.6 \%$; serious adverse events $10.6 \%$ vs $13.3 \%$ in dapagliflozintreated versus placebo, respectively), it did not result in a statistically significant reduction in organ dysfunction or death, or enhanced clinical recovery. ${ }^{1}$
The GRADE study, a pragmatic unmasked clinical trial to compare glucose-lowering efficacy and patient-centred outcomes of drugs (glimepiride, sitagliptin, liraglutide, insulin glargine) used as add-on to metformin therapy in over 5,000 people with type 2 diabetes commenced in May 2013 and completed in April 2021. ${ }^{2}$ This trial (symposium 28 June, $4.30 \mathrm{pm}$ ) showed that, over an average of 5 years, liraglutide and glargine were most effective at maintaining $\mathrm{HbA}_{1 \mathrm{c}}<7 \%$ whilst sitagliptin was the least effective; however, unlike glimepiride, liraglutide and sitagliptin 
were associated with weight loss. Preliminary results suggest that liraglutide also offered relative benefit of a reduction in the composite outcome of heart attack, stroke and other heart and vascular complications.

The results of the first phase 3 clinical trials with novel dual glucose-dependent insulinotropic peptide/glucagon-like peptide1 receptor agonist (GIP/GLP-1 ra) tirzepatide SURPASS 1, 2, 3 and 5 - were released in a symposium (29 June, 8am) which included a 30-minute live video question and answer session. ${ }^{3,4}$ Tirzepatide treatment was compared with placebo in SURPASS 1 (see 100OR and 81-LB), with semaglutide in SURPASS 2 (Abs 84-LB) and insulins degludec and glargine in SURPASS 3 (Abs 78-LB) and 5 (Abs 80-LB), respectively. In summary, once-weekly injection with tirzepatide ( $5 \mathrm{mg}, 10 \mathrm{mg}$ or 15 mg) dose dependently decreased $\mathrm{HbA}_{1 \mathrm{c}}$ (1.87-2.07\%; 20-23 mmol/mol), with >90\% of patients achieving an $\mathrm{HbA}_{1 \mathrm{c}}<7 \%$. Treatment also reduced body weight $(\sim 7-9.5 \mathrm{~kg})$ from baseline.

AMPLITUDE-O, a multinational study in more than 4,000 people with type 2 diabetes and cardiovascular and/or kidney disease, reported at a dedicated symposium (28 June, $2.15 \mathrm{pm}$ ). Treatment for a median of 1.81 years with once-weekly injections of the GLP-1 ra efpeglenatide (4 mg or $6 \mathrm{mg}$ ) with/ without a sodium glucose co-transporter 2 (SGLT2) inhibitor reduced the risk of heart attack, stroke or cardiovascular death by $27 \%$ and risk of kidney disease progression by $32 \%$ compared with placebo. Similar effects were observed in the presence and absence of a SGLT2 inhibitor and there were no serious side effects. ${ }^{5}$ The efficacy and safety of efpeglenatide were assessed in AMPLITUDE$\mathrm{M}$ (102-OR).

Sotagliflozin is a dual SGLT1/2 inhibitor. The initial results of the multinational phase 3 trials SCORED (a study in which type 2 diabetes patients with chronic kidney disease $( \pm$ albuminuria) were treated with sotagliflozin for a median of 16 months) and SOLOIST (a study in which type 2 diabetes patients recently hospitalised for worsening heart failure were assigned to sotagliflozin for a median of 9 months) showed that sotagliflozin treatment significantly reduced the composite risk of deaths from cardiovascular causes, hospitalisation for heart failure and urgent visits for heart failure.6,7 Originally reported in November 2020, the main results were shared for the first time with the diabetes community. A paired analysis of these studies indicated that sotagliflozin provides benefits across the

\section{Trial acronyms}

\begin{tabular}{|c|c|}
\hline AMPLITUDE-O & Effect of efpeglenatide on cardiovascular outcomes \\
\hline DARE-19 & DApagliflozin in REspiratory failure in patients with COVID-19 \\
\hline GRADE & Glycemia Reduction Approaches in Diabetes: a comparative Effectiveness study \\
\hline SCORED & $\begin{array}{l}\text { Effect of sotagliflozin on cardiovascular and renal events in patients with type } 2 \\
\text { diabetes and moderate renal impairment who are at cardiovascular risk }\end{array}$ \\
\hline SOLOIST & $\begin{array}{l}\text { Effect of sotagliflozin on cardiovascular events in patients with type } 2 \text { diabetes } \\
\text { post worsening heart failure (SOLOIST-WHF) }\end{array}$ \\
\hline $\begin{array}{l}\text { SURPASS } \\
\text { 1: in participants } \\
\text { 2: versus semagl } \\
\text { 3: versus insulin } \\
\text { 5: versus placebo } \\
\text { or without me }\end{array}$ & $\begin{array}{l}\text { A study of tirzepatide (LY3298176) } \\
\text { th type } 2 \text { diabetes not controlled with diet and exercise alone } \\
\text { de once weekly as add-on therapy to metformin in participants with type } 2 \text { diabetes } \\
\text { ludec in participants with type } 2 \text { diabetes } \\
\text { participants with type } 2 \text { diabetes inadequately controlled on insulin glargine with } \\
\text { rmin }\end{array}$ \\
\hline
\end{tabular}

range of albuminuria and decreases the risk of a heart attack by $32 \%$ and a stroke by $34 \%$ and, when initiated in patients hospitalised with acute heart failure, sotagliflozin reduced the risk of death from cardiovascular causes and hospitalisation or urgent visits for heart failure by $33 \%$. The growing body of data indicates that type 2 diabetes patients with kidney disease or heart failure should be assessed for initiation of this class of glucoselowering agent.

It is thought that the development of both efpeglenatide and sotagliflozin has been stalled due to the impact of COVID-19 and lack of financial investment.

\section{Diary date}

ADA 2022 is currently scheduled to take place at the Ernest $\mathrm{N}$ Morial Convention Center on the banks of the Mississippi (and next to a shopping mall) in New Orleans on 3-7 June (submit your abstract by 10 January). After nearly 3 years apart with altered waistlines and hairstyles, will we readily recognise each other - even unmasked? Hopefully it won't be necessary to again transition to a virtual meeting.

\section{References}

1. Kosiborod MN, Esterline R, Furtado RMH, et al. Dapagliflozin in patients with cardiometabolic risk factors hospitalised with COVID-19 (DARE-19): a randomised, doubleblind, placebo-controlled, phase 3 trial. Lancet Diabetes Endocrinol 2021;9:586-94. https://doi.org/10.1016/S2213-

8587(21)00180-7

2. Wexler DJ, Krause-Steinrauf $\mathrm{H}, \mathrm{Crandall} \mathrm{JP}$, et al, and GRADE Research Group. Baseline characteristics of randomized participants in the glycemia reduction approaches in diabetes: a comparative effectiveness study
(GRADE). Diabetes Care 2019;42:2098-107. https://doi.org/10.2337/dc19-0901

3. Rosenstock J, Wysham C, Frias JP, et al. Efficacy and safety of a novel dual GIP and GLP-1 receptor agonist tirzepatide in patients with type 2 diabetes (SURPASS-1): a doubleblind, randomised, phase 3 trial. Lancet 2021;398:143-55.

https://doi.org/10.1016/S01406736(21)01324-6

4. Frias JP, Davies MJ, Rosenstock J, et al, SURPASS-2 Investigators. Tirzepatide versus semaglutide once weekly in patients with type 2 diabetes. N Engl J Med 2021;385:50315. https://doi.org/10.1056/NEJMoa2107519

5. Gerstein HC, Sattar N, Rosenstock J, et al, for the AMPLITUDE-O Trial Investigators. Cardiovascular and renal outcomes with efpeglenatide in type 2 diabetes. N Engl J Med 2021;385:896-907. https://doi.org/10.1056/NEJMoa2108269

6. Bhatt DL, Szarek M, Steg PG, et al, for the SOLOIST-WHF Trial Investigators. Sotagliflozin in patients with diabetes and recent worsening heart failure. N Engl J Med 2021; 384:117-28. https://doi.org/10.1056/NEJMoa2030183

7. Bhatt $D L$, Szarek M, Pitt B, et al, for the SCORED Investigators. Sotagliflozin in patients with diabetes and chronic kidney disease. N Engl J Med 2021:384:129-39. https://doi.org/10.1056/NEJMoa2030186

Correspondence: Dr Caroline Day, Visiting Fellow, Diabetes Group, Aston University, Birmingham B4 7ET, UK E-mail: cday@mededuk.com

http://dx.doi.org/10.15277/bjd.2021.331 Br J Diabetes 2021;21:289-290 